\title{
ORIENTAL FOUNDATIONS OF PYTHAGOREAN STUDIES
}

\section{Ruzmatova Gulnoz Miraxrarovna}

Doctor of Philosophy, Professor of the Department of Philosophy and Logic, Faculty of Social Sciences, National University of Uzbekistan named after Mirzo Ulugbek, Tashkent, Uzbekistan.

\begin{abstract}
:
The article tried to cover in detail the socio-philosophical views of Pythagoras, the theory of knowledge, his teachings on the human psyche, oriental motives in the formation of his attitude to man. In the works of Pythagoras there are different interpretations of the myths about the afterlife of the human soul. The question of the eternity of the soul has been shown to be of great importance in the work of Pythagoras. Our goal is to analyze the socio-philosophical, moral views of Pythagoras, as well as the theory of knowledge, his views on man, based on sources. It is revealed that Pythagoras was influenced by ancient myths, the Upanishads, in creating his works.
\end{abstract}

Keywords:

Pythagorean philosophy, mythological cosmogony, soul eternity, soul migration, Samkhya philosophy, neo-Platonists, metampsychosis.

\section{Introduction}

It is well known that philosophy is an ancient branch of human spiritual life and knowledge. For almost three thousand years, people in all countries and regions have been in various forms, first in the form of myths, then in the form of certain systems of theoretical structures and whole concepts. crosses the question and tries to answer that question. Now, even at the beginning of the 21 st century, there are many theoretical concepts that try to answer the questions posed in the world. It should be noted that philosophical views of the past and present differ in many respects. However, there is also a commonality that makes it possible to equate these questions with philosophical questions. Also, the role of the spiritual ceremony of our ancestors in educating the younger generation in the era of globalization is invaluable. As the President Sh.M.Mirziyoev noted: "In such a sharp and dangerous situation, we, parents, teachers, the public, the community, must further increase vigilance and awareness on this issue. We must bring up our children ourselves, not leave them in the hands of others, and in carrying out these tasks we rely on the national traditions formed over the centuries, the rich heritage of our ancestors "[1, 23]. Indeed, the study of the philosophical views of great thinkers will always be a topical issue.

\section{Review of literature on the topic}

The work of the great philosopher of antiquity, the Greek philosopher Pythagoras, has been extensively analyzed in the philosophical, social, and historical literature, including the history of philosophy, by many scholars in a unique style, in keeping with his time. We can cite many examples of this, and from their genius ideas we can also find solutions that can fully meet today's demand. Also, A.F. Losev [8], S.Ya. Sheinman-Topstein [12], Jmud L.Ya. [3], T.Gomperts [6], L.Yu.Shreder [5], I.D.Rojansky [14] and other researchers' works, pamphlets, articles can be cited as examples.

\section{Research methodology}

Scientific and philosophical principles such as structural, theoretical-deductive reasoning, analysis and synthesis, historical and logical, comparative analysis were used during the research.

\section{Analysis and results}

Today, there is a growing interest in the problem of the influence of the East on ancient Greek philosophy. In particular, this state of influence arises as the only existence that leaves no room for discussion, and with the emergence of scientific works in which the authors strongly advocate the theory of the autonomous emergence of Western philosophy (in Ancient Greece) [2, 4- 
$5 ; 2,23]$. The debate in Western philosophy also applies to the controversy surrounding the assumption of the Eastern foundations of Pythagorean philosophy. In particular, the research of L.Ya. Jude, the author of one of the above-recognized works, on Pythagoreanism is extremely significant.

So long as it is known to us that a number of Greek Philosophers (Pythagoras, Democritus, Plato and others) set journeys to the East in quest of knowledge, we can conclude that the views of German philosopher and historian O. Spengler (1880-1936) and his esoteric predecessor E. Blavatskaya (1831-1891) on the inadequacy of the premise that Greek civilization is not actually the birthplace of philosophical thought are well grounded. Moreover, many contemporary scientists started to assert that Plato's "Atlantis" is not at all a figment of imagination and fantasy, that a number of civilizations have preceded the Greco-Roman civilization. The position that the Greek civilization is the birthplace of philosophy is still holding its prominence among the contemporary thinkers and we think that they are nothing but contemptible pieces of dogma.

Blavatskaya writes that: "Every culture, which is merited to bear the name "civilization", had esoteric doctrines". In this respect, we consider the Vedic doctrines, the doctrine of Avesta, and the religious doctrines of ancient Egypt and Babylon much earlier than the Greek philosophy. According to Blavatskaya, philosophy in Balkan Peninsula emerged as a result of the Orpheus' doctrine, which was thought out after his Indian voyages and this doctrine served as a basis for many philosophical schools on the planet.

According to the explanation provided by the Indian philosopher and political theorist S. Radhakrishnand, "The theoretical proximity of Avesta to the Vedas is greater than that of the Vedas to the translations of the Vedas into the Sanskrit" and "the historical roots of the Indian thought goes back to the Aryan invaders from the Central Asia". One of the founders of Neo-
Platonism, Ammonius Saccas, called the wisdom "religion", and asserted that "the secret doctrine of the religion of wisdom is laid out in the Book of Hermes, and Pythagoras and Plato derived their knowledge from that source". If we consider Hermes as the Prophet Idris in Islamic sources, we can assert that, based on Ammonius Saccas, ancient Greek Wisdom was partly inspired by mystical (esoteric, based on revelation) sources. An excellent example for this is the book "The Greeks and the Irrational" by the English classical scholar Eric Robertson Dodds, called, especially the Third Chapter titled "The Blessings of Madness", in which ancient Greek philosophers, particularly Socrates, argue that madness or ecstasy is the greatest gift to humanity by the Gods. Moreover, the Sufism also considers "khol" or ecstasy as "a gift from God" $(8,149)$.

One of the most prominent Sufi thinkers, Sh. Suhravardi, in order to explain the nature and the history of wisdom, argues that "Complete (deep) and true knowledge, which is the art of ishrok (illumination), is the knowledge which is attained by ascetism and chanting of spiritual texts, and the ancient Greeks obtained this knowledge from the son of Zeus, Hermes. The Hermes obtained this knowledge from the heavens and this is the knowledge which was constantly swapped between ancient Greek, Arab and Iranian thinkers". Hermes is mentioned in Islam as Idris, the son of prophet Sif (Shis).

Furthermore, the maxim "Know Thyself" is very synonymous with the a passage from the Hadith, which reads "One who knows himself knows the Allah", and this maxim was first proposed by the ancient Greek philosophers of the $6^{\text {th }}$ century BC. Thus, this maxim has very deep roots as an esoteric knowledge. Its source directly goes to the Divinity or the Revelation. So, it is unwise to show it as a thing which is originated in a specific region in a specific point of time in history. Instead, it is proper to conclude that this knowledge has been known to man ever since he achieved the Divine Revelation. The art of 
Revelation is passed to Muhammad the Prophet from the Adam.

Based on the formulations, which we provided above, we can assert that there actually were the esoteric aspects of the ancient Greek philosophy and this philosophy actually emerged on the esoteric grounds and replenished and richened by the new doctrines which was imported from the East. At the same time, this knowledge had also an exoteric aspect which was expressed in logical operations and words. Ancient Greeks called this exoteric aspect of their philosophy "Logos" or "Word". It has an equivalent in Islamic philosophy and it is called "Kalom" or "the Knowledge of Khol".

The emphasis in contemporary Western philosophy is now mainly on the exoteric, or the rational-logical aspects of this two-sided coin. An interpretation of the myths, provided by Plato illustrates the presence of esoteric (revelation) traditions in ancient Greek philosophy. He argued that it is impossible to know the myths rationally, and one can only have faith in them by believing in Orpheus, Homer or Hesiod and other poets, or one can only perceive it as something which is not perceived with the help of sense organs, but only through intuition.

The fact that all the literature concerning the history of philosophy has mythology, which accumulated all the forms of art and creativity in itself and sometimes called "pre-philosophy" serves to strengthen our above stated position.

How fair and reasonable is it to try to disprove the theory of the influence of the East on Pythagorean studies? The influence of the East on the teachings of Pythagoras is based on the research of E.Tseller [4]. All the evidence can be grouped into several points:

Proponents of the "Eastern" view are accused of being too distracted by speculation. They are opposed by researchers who prefer not to believe in more than the inevitable facts. Such oppositions are extremely strict.

Indeed, history can be distorted by unfounded assumptions. But they try to contradict the truth through any assumptions. After all, the "cut-off" version of the interpretation of history, if it is firmly declared that there are no unspoken ideas, is nothing but a hypothesis in the essence of the matter.

The idea of comparing history with the archaeologist who found the statue of a woman who lost her head as a result of an injury over time, which is great for a more impressive classification, arises. It would be ridiculous if this statue admitted that it must have a creature's head. Wouldn't it be more ridiculous if it were said that the reason why this statue was like that was that in ancient times all people were headless?

Thus, when there is no irrefutable proof to fill the "white spots" of history, all logically put forward and grounded assumptions can be true. And each of them needs to be investigated until there is irrefutable evidence to "support" or "oppose" it.

As one of the main proofs, E. Tseller, who advocated the independent origin of all Greek philosophy, acknowledged that there were no incomprehensible theories and signs that were alien to him in Greek philosophy in general, including Pythagoreanism: “... Greek philosophy acquires a completely national classification. ; ... there is no struggle between himself and the stranger, there is no use of incomprehensible formulas " $[4,23]$. This argument, as imagined, is refuted by the most reliable "criterion of truthfulness," that is, by historical truthfulness. Consequently, despite the disagreement of the researchers, one thing is certain: scientists have repeatedly and repeatedly tried to prove the original ideas in the teachings of some ancient Greek philosophers, including Pythagoras, and assimilated them.

L.Shreder, T.Gomperts and A.Furtvengler [5; 6; 7;], while convincingly pointing out in their research that Pythagoras' theory of metampsychosis (i.e., the theory of the transformation of the soul) is different, refutes Tseller's contradictory point of view: " it cannot be explained " $[5,6]$. As a result of a comparative 
analysis of Hindu and Pythagorean sources, scholars have come to the conclusion that the idea that an unclean spirit in a changing body is expelled for punishment until it is purified originated in Indian soil and is completely alien to Greek psyche [6, 125-126; 7, 263]. The disbelief in the strict instructions of the neo-Platonists in researchers of Pythagorean creativity can be explained in two ways. First, it was believed that the stories of neo-Platonists, especially Porphyry and Yamvlix, did not provide strongly exaggerated and reliable information. Such observations are based on their religious and ideological reasons:

"If the Greek philosophers of the Christian era had supported the thesis that philosophy originated with the sages of the East, ... it still could not prove anything conclusively, because these philosophers had already lost faith in classical philosophy, and their writings were inconsistent with Christian scriptures. - those who opposed ... "[2, 4]. For example, A.F. Losev, while refraining from unfounded opinions, his conclusion "sounds" in a different tone: "... Yamvlix, like all other neo-Platonists, reformed, purified, inspired and praised the ancient heritage as much as possible" [8, 171]. At the same time, it is easy to see that concepts such as "purification," "inspiration," and "praise" do not in any way imply a violation of doctrine. When it comes to reform, then it is in this context that neoPlatonists put forward a perception of the world within a worldview that is modern to them. In other words, if the neo-Platonists also oppose the Christian religious current, it does not mean that they have yet used inappropriate means and distorted the historical evidence. The second aspect of distrust of subsequent sources is reflected in the following: Nothing was known in ancient legends about Pythagoras' travels to the east $[4,22,50]$. It would be more fair to add a little clarity to this: the legends about Pythagoras' journey to the East are not known to us from his contemporaries. Another reason is that our knowledge of the use of oriental writings and translations by the Greeks is insufficient $[2,4]$.

In this case, the role of conflicting foundations is first and foremost in the secrecy of esoteric traditions in Pythagorean studies and, of course, even the existence of early oriental sources, and especially Pythagorean writings, if any $[9,141,444]$. The second is that oral oriental traditions in the transmission of knowledge have not been sufficiently evaluated by modern researchers [7, 263]. The latter framework involves a certain proportion of contradictions. On the one hand, scientists study mathematics, astronomy, and so on. they unilaterally recognize the enormous influence exerted by the East on the formation of such spheres in Greece. There is no doubt about the existence of mythology (myth) and mythological cosmogony in the peoples of the East. On the other hand, the peoples of the East could not comprehend the philosophical observations of the Greeks, for none of these peoples "had a philosophy, nor did any attempt to give a natural explanation of what could serve as a source or example for Greek thinkers for their own interpretations" [4, 33].

Admittedly, the question of the recognition of Eastern philosophy is rare today, including [10; $11,41 ; 12,7 ; 13]$. In addition, orientalists are talking about the contradiction between the facts being studied and the facts. For example, S.Ya. Sirkin, a translator and commentator on the Upanishads (including the first, dating to the 7th century BC), says: 14, 30]. Therefore, given the recent advances in Oriental studies, it is fair to say that the evidence that Tseller is studying has lost its credibility today.

Thus, none of the evidence against the hypothesis of the eastern origin of the Pythagorean doctrine is sufficient. Moreover, Tseller himself realized this, because his conclusions about the source of Pythagoras' knowledge were ambiguous: "... where he gathered his knowledge - it is unknown to us ...... it is necessary to calculate with assumptions ... " $[4,50]$. 
Like intuition, the analysis conducted acknowledges the author of this work to pay serious attention to the evidence that serves the benefit of the Eastern origins of the doctrine. The common sense, which can only be based on historically conflicting evidence, encourages a deeper look at the field of comparative analysis that has already been carried out by a number of researchers.

Most of them stem from two of the most important foundations. First, the Pythagorean doctrine creates the notion of a foreigner (foreigner) for the Greek thought of the time. This idea has been proved very convincingly and in detail by A. Schroeder, T. Gomperts and A. Furtvengler [5: 2, 26; 6: 125-126; 7: 263], for there was no need for him to return. Gomperts rightly points out that "the problem lies in the question of which nation and which religion the sage adopted his teachings from" [6, 126]. Second, the similarity of Pythagorean views with some ancient Eastern teachings amazes researchers. Thus, according to Gladish, the Pythagorean worldview has its origins in China, and according to Ret, according to Egypt [5, 3]. However, Retda was a long-time predecessor, and Herodotus, while narrating the customs of the Egyptians, "although they actually belonged to Egypt and Pythagoras, they endorsed the socalled' orfik 'and' waqf 'ideas" [9, 139].

A.Voloshinov, I.Rozhansky and others were inclined to conclude that Pythagoras was more likely to have studied in Egypt and Babylon, so, recognizing the Eastern influence on his views, "such an option allows us to describe some aspects of early Pythagoreanism" [6: 5; 14:13].

In addition to Egypt and Babylon, Gomperts mentions India: "We find great similarities between the Pythagorean and Hindu teachings about the migration of the soul. assumptions should not seem dangerous to us "[6: 126-127].

The author of this article is closer to the view that Pythagoras was familiar with the teachings of a number of mature scholars of the time: Indian, Persian, Babylonian, and Egyptian. However, of course, given the scale of such a problem, it requires separate research. In the context of this work, it seems appropriate to limit the study of thought analysis to the relationship between Pythagoreanism and Indian philosophical traditions. In particular, the hypothesis of the Indian influence on the doctrine of Pythagoras gained a large number of supporters. E.P.Blavatskaya in this direction. A number of scientists such as L.Yu.Shreder, A.Furtvengler, T.Gomperts, S.Y.Sheinman-Topstein, V.P.Fomin conducted serious researches $[5-7 ; 12 ; 15 ; 16]$.

Thus, E.P. Blavatskaya admits that Pythagoras is related to the teachings of the Indian Brahmins, and that the laws of Mony are somewhat similar to the Pythagorean numerical theory [15, 23-24]. S.Ya. Sheinman-Topstein speaks about the harmonization of the mystical teachings of the Vedas in Pythagoreanism with the mathematical traditions of Babylon [12, 34]. L. Schroeder tries to connect Pythagorean philosophy with the Indian Samkhya philosophical system $[5,52]$.

T. Gomperts and A. Furtvengler emphasize the connection of Pythagoreanism with the ancient Indian religious and philosophical traditions and substantiate the possibility of this connection in general. Assumptions that Pythagoreanism is related to Indian Vedic traditions are more plausible today. S.Ya.Sheinman-Topstein and V.P.Fomin, on the other hand, prove that the ancient Upanishads are similar to a number of laws of Pythagoreanism. The most detailed work in this direction belongs to L. Schroeder. Admittedly, Tseller did not take into account Schroeder's attempt to prove the successful oriental origins of Pythagoreanism. One can partially agree with his views: The proofs of the connection between the philosophy of Samkhya and the Pythagorean doctrine, although extremely interesting, were not so convincing. It should be noted, however, that Schroeder's proofs of the similarity of Pythagoreanism with the Indian worldview of the time were extremely 
convincing to refute them. To confirm or refute the validity of this hypothesis, it would be expedient to systematize the results of research on this subject, as well as doxographic data on the expected connection of the founder of Pythagoras with the East. Evidence from ancient Greek authors about Pythagoras' travels to India has not survived. There are recent legends about this.

Evidence from Aristoxen [9, 141] testifies that Clement Alexandrius and Diogenes Laertsky testified that Pythagoras' ancestors were probably Syrians or Phoenicians, and that A. Mann's assertion of Pythagoras: [17, 58]. There is also a legend that connects Pythagoras' mentor Ferekid Sirossky with the East: "In Hellas, he was the first to acknowledge that the human soul is immortal and capable of moving from one body to another" $[17,51]$.

While T. Gomperts [6, 126-127] and A. Furtvengler [7, 263] dwell on the influence of Indian philosophy on Pythagorean studies, there is no need to assume that Pythagoras himself visited India, since he apparently assimilated these ideas through the spread of the Persians. they reach. After all, in the VI century BC it was through Persia (Iran) that the road connecting Greece and India passed. Furtvengler recalled the existence of this connection in one of the archeological evidences while recounting the ancient Greek ships of the seventh century found in northeastern India [7, 263].

Scheinmann-Topstein also predicts the possibility of Indian influence through Mesopotamia: "It is possible to talk about the mutual assimilation of ancient Greek and ancient Indian ideology...", therefore, "trade between the Mesopotamian states and the Indian Valley from the VII century BC -The trade was in full swing, and the ancient Greek thinkers traveled to the east and became acquainted with Babylonian astronomy " $[12,113]$. It should not be forgotten the option of Pythagoras himself visiting India.

Thus, E.P. Blavatskaya, while studying ancient laws in India, notes that Pythagoras learned esoteric sciences from Indian Brahmins, and in India he is still known as Javanacharya ("Ionian teacher") [18, 374].

In Pythagoreanism, the doctrine of metampsychosis, that is, the transformation of the human soul into another form, is one of the most striking examples of the Indian worldview. Schroeder states: "We can say with complete confidence that the only people who believed in the migration of the soul before Pythagoras and taught about it were the Indians" [5, 16].

The arguments of Schroeder, Gomperts, and Furtvengler on this issue can be considered perfect $[5,3-17 ; 6,123-127 ; 7,261-263]$. Tseller has a view of the possibility that this theory of the Pythagoreans was inherited through the tradition of orphism. Schroeder flatly denies such an opportunity, and there are good reasons for it.

While acknowledging the similarities between Pythagorean and Orthodox teachings (including cosmogonic myths and theories about the reshaping of the soul), the researchers also acknowledged the significant differences between them. Detailed elaboration of these issues is covered in the works of English scientists F.M. Cornford and W. Gatri, as well as A. Furtwengler and T. Gomperts [6, 123-126; 7, 263; 20, 8].

Pythagoras' assumptions about the reformation of orthographic ideas, or especially the independent development of the theory of metampsychosis, are highly questionable because "the similarity between the Hindu and Pythagorean doctrines of the transmigration of the soul ..." and in formulas that express beliefs such as "circle" and "circle" at birth. Here, it is clear that we are not just coincidental "[6, 126]. In India, the doctrine of reformation or reincarnation traditionally existed as early as the Upanishads, which date back to the VIII-VII centuries BC [21, 17]. In India, the doctrine of reformation or reincarnation traditionally existed as early as the Upanishads, which date back to the VIII-VII centuries BC $[21,17]$.

T. Gomperts also comments on the significant differences between Pythagorean and Orthodox approaches to metampsychosis, calling 
Pythagorean and Orthodox doctrines "the main single stream in the representation of men and women (recognized by the author)" [6,123]. That is why it was the acquaintance with the Orthodox doctrine that led Pythagoras to become acquainted with the laws of the East in the future.

Studies by Schroeder, Gomperts, and Scheinmann-Topstein $[5 ; 6 ; 12]$ On the connection of the Pythagorean doctrine with the traditional Indian doctrines, the migration of the soul and the individual responsibility of man for his own actions (according to Indian terminology, the doctrine of rewards for reincarnation and karma), blood sacrifices, vegetarianism (not meat), and the detailed similarity of ideas about the existence of separate methods of preparing the body and soul for the correct comprehension of valuable knowledge (memory exercises, so-called Pythagorean prohibitions, etc.) and the existence of verbal esoteric traditions of knowledge transmission.

In addition, L.Yu. Schroeder defines Pythagoreanism as related to the teachings of the Brahmins in some very broad fields of knowledge. Thus, based on Vedic literature, especially Brahmanical literature, as well as Cantor's research on the history of mathematics, Schroeder said that "Brahmins of the Vedic period knew Pythagoras' theorem and explained it according to Euclid's method... concluded [5, 37-38]. It was in the Brahmins that Schroeder found the "concept of irrational quantities that the Greeks believed to have been invented by Pythagoras" and the technique of turning a right angle into a gnomon $[5,39]$.

Another similarity in Pythagorean and Indian knowledge is reflected in the teachings that the world consists of three worlds and five elements [5, 45-56, 61]. Finally, Schroeder acknowledges the mystical-symbolic classification of the Pythagorean system, which is in many respects similar to the methods of "the science of sacrifice that has come down to us in Yagkurveda and Brahmans, the ancient Brahmanic observation" [5, 62-64].
Conclusions and suggestions

Thus, according to the hypothesis based on the systematization of research, a lot of evidence testifies to the fact that a number of rules of Pythagoreanism are consistent with the ancient Indian teachings. Consequently, the hypothesis of the oriental origin of Pythagoreanism is in many cases based on convincing evidence. This assumption, therefore, has more of an unquestionable right to exist than that of its opponent. Therefore, there is a need to reconsider the reliability of some subsequent sources in order to try again to "read" the Pythagorean doctrine.

Within the framework of the research, its conclusions can be used to expand sociophilosophical thinking, to write monographs, relevant sections of textbooks, to form an independent opinion, to form a positive attitude to the history of philosophy, the theory of knowledge. Today, the study and analysis of various doctrines, the ability to draw the right conclusions in accordance with the requirements of our time and use them to expand the scientific and spiritual worldview of our youth, to develop them into harmoniously developed people.

\section{References}

[1] Mirziyoev Sh.M. The rule of law and the protection of human interests are the key to the development of the country and the well-being of the people. - $\mathrm{T}$. Uzbekistan, 2017.

[2] Reale J., Antiseri D. Western philosophy from the origins to the present day. Antiquity. - M .: Thought, 1997.

[3] Zhmud L.Ya. Pythagoras and his school. L., 1990.

[4] Zeller E. Essays on the history of Greek philosophy. - SPb., 1996.

[5] Schroeder L.Yu. Pythagoras and the Indians // Journal of the Ministry of Public Education. - 1988. - No. 10-11.

[6] Gomperts T. Greek thinkers: Per. with him. D. Zhukovsky and E. Gertsyk / Scientific. ed., comments, approx. and 
foreword. A.V. Tsyba: In 2 volumes. Vol. 1.- SPb., 1990.

[7] Furtwängler A. Die Antiken Gemmen. III. 1998.

[8] Losev A.F. Dictionary of Ancient Philosophy. - M .: Thought, 1995.

[9] Fragments of the early Greek philosophers. Part 1 / Ed. I. D. Rozhansky. - M .: Thought, 1989.

[10] Lukyanov A.E. Formation of philosophy in the East (Ancient China and India). - M $\therefore$ Thought, 1992 .

[11] Radhakrishnan S. Indian philosophy. T. 1: Per. from English. - $\mathrm{M}$ : Thought, 1956.

[12] Sheinman-Topstein S.Ya. Plato and Vedic philosophy. - M .: Nauka, 1978.

[13] Shokhin V.K. Brahmanical philosophy. Initial and early classical periods. - M .: Thought, 1994.

[14] Rozhansky I.D. Early Greek Philosophy // Fragments of Early Greek Philosophers. Part 1 / Ed. I. D. Rozhansky. - M .: Thought, 1989.

[15] H.P. Blavatsky. Isis Unveiled: In 2 volumes. T. 1. - M .: Antiseri, 1993.

[16] Men A.V. History of religion: In search of the Way, Truth and Life: In 7 volumes. Vol. 4: Dionysus.

[17] Logos, Destiny: Greek Religion and Philosophy from the Age of Colonization to Alexander. - M .: Nauka, 1992.

[18] Stolyarov A.A., West M.L. Early Greek Philosophy and the East // Modern Foreign Studies in Ancient Philosophy. M .: Thought, 1978.

[19] HP Blavatsky Theosophical dictionary. M .: Antiseri, 1994.

[20] Pythagorean Golden Poems with a commentary by the philosopher Hierocles: Per. from ancient Greek. I. Peter. - M .: Thought, 1996.
[21] Syrkin A.Ya. Early Upanishads and Briharadanyaka // Briharadanyaka Upanishad. - M .: Thought, 1992

[22] Ruzmatova G. Eastern melodies in the text of Plato // International Journal of Recent Technology and Engineering. Vol. 8, Issue-2S6, July, (2019). -P. 444-448. IJRTE. ISSN: 2277-3878.

[23] Ruzmatova G. Comparativist analysis of Representations about Will in View of Friedrich Nitzsche and Jalaliddin Rumi // International Journal of Psychosocial Rehabilitation, Vol. 24, Issue 04, 2020. ISSN: 1475-7192. -P. 3215-3227. 